\title{
Optimization of freshwater microalgal biomass harvest using polymeric flocculants
}

\author{
Franziska Bleeke • Malgorzata Milas • Dominik Winckelmann • \\ Gerd Klöck
}

Received: 17 March 2015/ Accepted: 20 June 2015/Published online: 10 July 2015

(C) The Author(s) 2015. This article is published with open access at Springerlink.com

\begin{abstract}
Although microalgae show a great potential in the biotechnology sector, high production costs have limited industrial applications. Biomass harvest is one of the major bottlenecks in microalgae cultivation due to high energy inputs which are needed to separate the cells from the surrounding media. Chemical flocculation is considered to be a reliable resource to improve cost-effectiveness in the downstreaming processing. Flocculation efficiency is dependent on several factors such as the polymer type and charge as well as on the microalgae species. In the present study, 15 polyelectrolytes were tested for their potential to harvest algal biomass. Cationic, anionic and nonionic flocculants were tested in different amounts at varying incubation times to determine the adequate conditions needed. By testing the three chlorophytes, Chlorella sp., Scenedesmus acuminatus and Chlamydomonas reinhardtii, the influence of different sizes, morphologies and motilities of the flocculation efficiency was verified. Furthermore, the biocompatibility of an efficient flocculant was tested in a recycling experiment over a period of 8 weeks.
\end{abstract}

Keywords Microalgae $\cdot$ Biomass harvest $\cdot$ Chemical flocculation $\cdot$ Polyelectrolytes $\cdot$ Microalgal biotechnology $\cdot$ Polymeric flocculants

\section{Introduction}

Microalgae are microscopically small photosynthetic protists with rising significance in the biotechnology sector. According to Posten and Walter (2012), microalgae have a five times higher biomass productivity per hectare compared to terrestrial crops (Posten and Walter 2012). Furthermore, they can be grown on non-arable land and produce biomass which can serve as food or feedstock or as potential substrate for biofuel production (Chisti 2007; Mata et al. 2010).

Although microalgae cultivation displays great potential, high production costs have limited industrial application. A major factor is the cell harvest, which contributes to $20-30 \%$ of the biomass production costs (Grima et al. 2003; Mata et al. 2010; Uduman et al. 2010). Large volumes have to be processed, since the

\footnotetext{
F. Bleeke $(\bowtie)$

Jacobs University, 28759 Bremen, Germany

e-mail: franziskableeke@hotmail.de

F. Bleeke · D. Winckelmann · G. Klöck

Institute of Environmental Biology and Biotechnology, University of Applied Sciences Bremen, 28199 Bremen, Germany

M. Milas

Gdansk University of Technology, 80-233 Gdansk, Poland
} 
concentration of cells is usually low at $0.5-2.5 \mathrm{~g} \mathrm{l}^{-1}$ (Grima et al. 2003). Commonly used separation processes are a combination of filtration, flotation or flocculation, followed by a final centrifugation step. To separate the cells from the surrounding media, high-energy inputs are needed, often exceeding the energy content of the harvested biomass (Grima et al. 2003; Uduman et al. 2011; Wijffels and Barbosa 2010).

Increasing the efficiency at low-energy demands within the harvesting process is a major challenge in microalgal biotechnology. In flocculation, the cells coagulate and larger particles are produced with a higher settling velocity due to the higher density of the flocs. Flocculation can be achieved in several ways. Numerous studies have been published on the use of electrocoagulation (Lee et al. 2013; Uduman et al. 2011; Vandamme et al. 2011), pH-induced flocculation (Vandamme et al. 2012; Wu et al. 2012; Zheng et al. 2012) or bioflocculation using bacteria (Lee et al. 2009), filamentous fungi (Zhou et al. 2013) or another flocculating algae to floc a non-flocculating algae (Salim et al. 2011) for biomass harvest.

In chemical flocculation, a chemical coagulant is added to the algal suspension (Xu et al. 2010). Organic and inorganic flocculants like polyelectrolytes and metal salts were investigated. Aluminum, ferric and zinc salts were tested (Papazi et al. 2010) and compared with polyelectrolytes (Gerde et al. 2014; Granados et al. 2012; Papazi et al. 2010; Sirin et al. 2012). Comparative studies showed that higher flocculation efficiencies (FE) were achieved with polyelectrolytes than with metal salts (Gerde et al. 2014; Granados et al. 2012). Besides the lower FE, another disadvantage of the use of metal salts is the high concentration of metals in the algal biomass after harvest. Metal residues may impede the use of certain applications such as animal feed (Grima et al. 2003). Polymers are commonly used in wastewater purification processes and preferred for algal harvest, because lower amounts are needed and non-toxic and biodegradable substances are available (Granados et al. 2012). Polymeric flocculants are commercially available with cationic, anionic and nonionic charges in different charge densities, whereas cationic flocculants are considered to be the most effective for algal harvest (Granados et al. 2012; Tenney et al. 1969). The effect of different flocculants on several algae species has also been described. The results showed high variability with respect to the algae species and the nature of the flocculant (Gerde et al. 2014; Granados et al. 2012; Harith et al. 2009; Papazi et al. 2010; Rashid et al. 2013; Sirin et al. 2012).

Chlorella sp., Scenedesmus acuminatus and Chlamydomonas reinhardtii are commonly used laboratory strains and model organisms for algal research (Harris 2001; Mandal and Mallick 2009; Safi et al. 2014; Sanchez et al. 2008). By testing these three chlorophytes the influence of different sizes, morphologies and motilities of the flocculation efficiency were analyzed.

In the present study, 15 polymeric flocculants were compared to test the following hypotheses. Are cationic flocculants more effective compared to other polymeric flocculants (H1)? Do closely related species show similar flocculation behavior (H2)? Is a reuse of the media after cell separation by flocculation applicable (H3)?

\section{Materials and methods}

Microalgae and culture conditions

The experiments were carried out using the freshwater chlorophytes Scenedesmus acuminatus, Chlorella sp. and Chlamydomonas reinhardtii from the culture collection of the University of Applied Sciences Bremen. The cells were grown at $22{ }^{\circ} \mathrm{C} \pm 1$ in a culture volume of 21 in Wuxal liquid medium (WM)(Winckelmann et al. 2014) without $\mathrm{pH}$ control. Bottles were equipped with aeration hoses providing continuous bubbling with compressed air at a flow rate of approximately $2.31 \mathrm{~min}^{-1}$. Every 3 days, $600 \mathrm{ml}$ of the culture was used for the experiments and fresh medium was added to the remaining culture. Illumination was offered $24 \mathrm{~h}$ per day by fluorescent lamps (OSRAM L $30 \mathrm{~W}$, warm white) placed in front and behind the algae cultures (light intensity, $50 \mu \mathrm{mol}$ photons $\mathrm{m}^{-2} \mathrm{~s}^{-1}$ ).

Flocculants

Stock solutions of 15 polymeric flocculants with cationic, anionic and nonionic characteristics were prepared according to the manufacturer's recommendation, dissolved in water and stored at $4{ }^{\circ} \mathrm{C}$ for a maximum of 2 weeks. 
Flocculation experiments

Before each experiment, the $\mathrm{pH}$ of the sample from the algae culture was carefully adjusted to 7.0 by adding $1 \mathrm{~N} \mathrm{HCl}$. The cell number was determined using a Thoma counting chamber (Paul Marienfeld GmbH \& Co. $\mathrm{KG}$, Lauda-Königshofen, Germany) and subsequently adjusted to $1 \times 10^{7}$ cells $\mathrm{ml}^{-1}$ by dilution with tap water. Flocculation experiments were evaluated using jar tests (Granados et al. 2012; Hudson and Wagner 1981; Vandamme et al. 2010). $100 \mathrm{ml}$ Erlenmeyer flasks were filled with $100 \mathrm{ml}$ of algal suspension (Fig. 2). The flasks were stirred at $150 \mathrm{rpm}$. One type and concentration was used in each flask. Once the flocculant was added, the culture was mixed for $1 \mathrm{~min}$ at $250 \mathrm{rpm}$, to allow flocculant distribution. After $1 \mathrm{~min}$, the mixing speed was reduced to $50 \mathrm{rpm}$ for $2 \mathrm{~min}$, to support floc formation, followed by a settling phase without agitation. Samples were taken directly after the flocculant distribution and after 2, 10, 30 and 60 min from $3 \mathrm{~cm}$ under the culture surface. Optical density was measured at $750 \mathrm{~nm}$ (Genesys 20, Thermo Scientific, Walthman, USA) and the flocculation efficiency (FE) was determined as follows:

$$
\text { Flocculation efficiency }=\left(\frac{\mathrm{OD}_{T 0}-\mathrm{OD}_{T 1}}{\mathrm{OD}_{T 0}}\right) \times 100,
$$

where $\mathrm{OD}_{\mathrm{T} 0}$ is the initial optical density before starting the flocculation and $\mathrm{OD}_{\mathrm{T} 1}$ is the optical density of the sample at a certain point of time during the process. Samples showing OD values above 0.5 were diluted with tap water for the measurements to assure linearity.

Media reuse after flocculation

A recycling experiment was conducted to investigate the potential negative impact of flocculant residues on algal growth when the media are recycled. Flocculant PK55H was chosen for the media reuse experiment. The experiment was conducted in triplicate using the microalgae Chlamydomonas reinhardtii under the same cultivation setup as described in "Microalgae and culture conditions". Over a period of 8 weeks, the cultures were harvested weekly by flocculation (Fig. 1a) or centrifugation (Fig. 1b), whereas the centrifugation served as positive control displaying the growth without the impact of the flocculant. The volume of the recycled media was dependent on the optical density of the culture. After cell separation, the culture supernatant was enriched with concentrated WM and led back into the culture vessel. The final optical density in the culture after media recycling was 1.5 at $750 \mathrm{~nm}$.

Cell growth was monitored by optical density measurements at $750 \mathrm{~nm}$, cell count determinations and dry biomass determination. For dry biomass determination, $10 \mathrm{ml}$ of the algal culture was filtered through a previously balanced Whatman GF/C glass fiber filter (Whatman, Maidstone, UK). The filters were dried in an oven at $80^{\circ} \mathrm{C}$ for $12 \mathrm{~h}$ and weighed afterward. The difference in weight was calculated and multiplied by 100 resulting in the dry biomass expressed in $\mathrm{g} 1^{-1}$.

\section{Result and discussion}

The flocculation process consists of different stages as displayed in Fig. 2. This shows the different phases during a flocculation process using S.acuminatus with the flocculant PK55H. After the addition of the polymer (a), the mixing speed was increased for $1 \mathrm{~min}$ to allow flocculant distribution (b). The flocculant adsorbs to the cell surface and the suspension is destabilized (c) and floc formation can be observed (d, e). The flocs grow

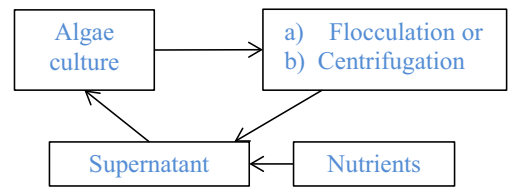

Fig. 1 Media reuse experiment. Over a period of 8 weeks, the cultures were harvested weekly by a flocculation or b centrifugation. After cell separation, the culture supernatant was enriched with concentrated WM and led back into the culture vessel 


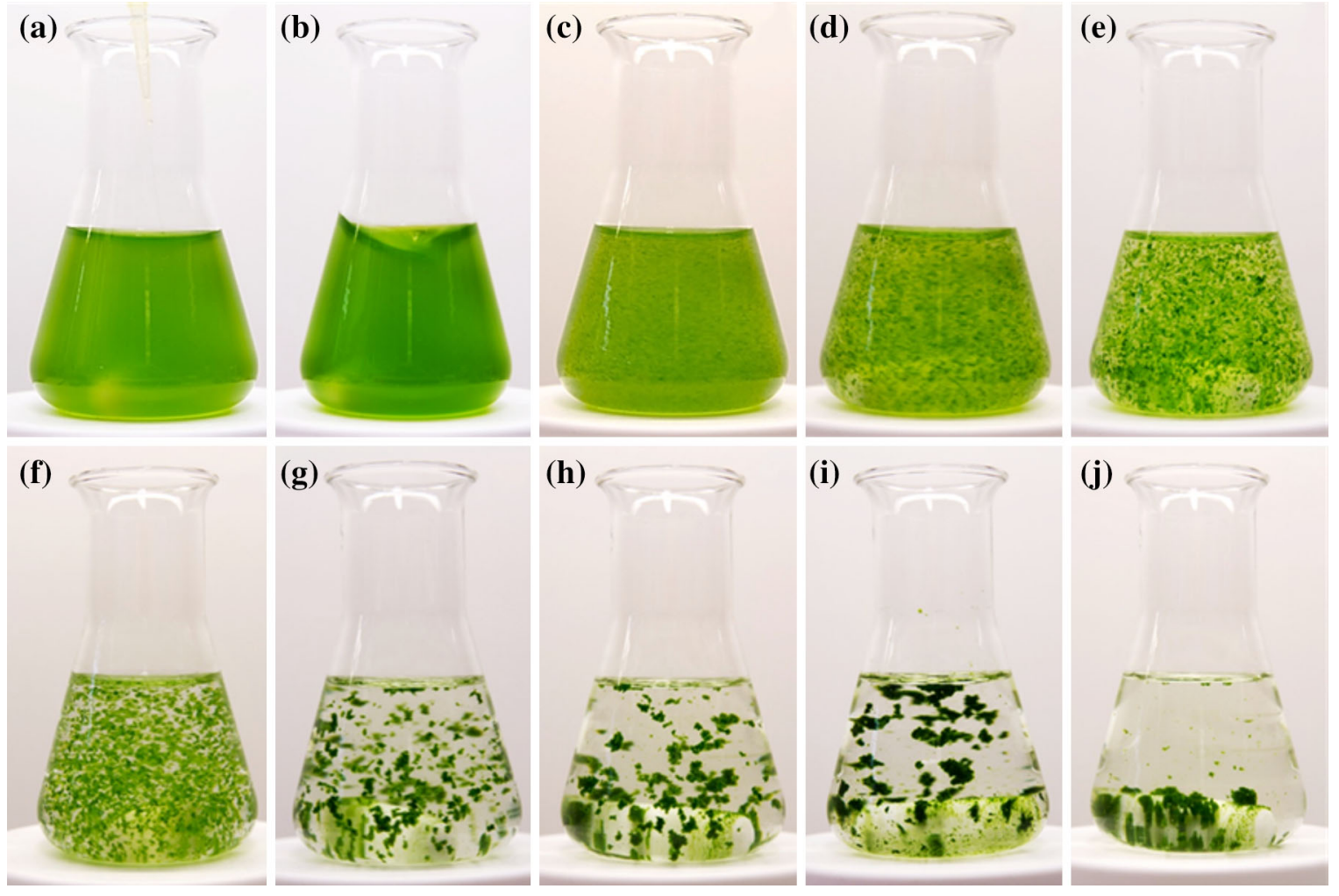

Fig. 2 Flocculation of Scenedesmus acuminatus using flocculant PK55H. a Addition of flocculant, b flocculant distribution, $\mathbf{c}$ destabilization of the suspension, $\mathbf{d}$, e floc formation, $\mathbf{f}-\mathbf{i}$ floc growth and $\mathbf{j}$ settling of the flocs

due to successive collisions and adsorption of microflocs ( $\mathrm{f}-\mathrm{i})$. In a last phase, the agitation is stopped and the flocs are allowed to settle (j). According to the manufacturer, $\mathrm{PK} 55 \mathrm{H}$ is a strong cationic polymer producing large dense flocs (Fig. 5i, c).

The flocculant concentration in the suspension significantly affects the FE. If a destabilization of the algal culture is not visible after flocculant addition, the amount of flocculant can be increased.

Flocculation experiments were conducted determining the $\mathrm{FE}$ at different dosages for all 15 flocculants investigated (Table 1). Furthermore, the optimal incubation time was identified by monitoring the FE at different time points. In each experiment, the flocculant was added and the optical density was measured after $0,2,10,30$ and $60 \mathrm{~min}$. The settling of the microalgae was monitored as a result of flocculation. Figure $3 \mathrm{a}$ shows the flocculation of Chlorella sp., Scenedesmus acuminatus and Chlamydomonas reinhardtii with the cationic flocculant KW100. Increasing flocculant concentration causes the FE to rise. Figure 3a shows the results for Chlorella sp. at concentrations between 5 and $40 \mathrm{mg} \mathrm{l}^{-1}$ of flocculant in the algae culture. Whereas $5 \mathrm{mg}^{-1}$ did not even reach a $\mathrm{FE}$ of $50 \%$, concentrations above $25 \mathrm{mg}^{-1}$ resulted in a recovery rate of $90 \%$. The incubation time, however, differed significantly. Increasing the amount of flocculant added reduces the incubation time needed to reach $90 \%$ FE. $60 \mathrm{~min}$ was needed at $25 \mathrm{mg} \mathrm{l}^{-1}, 10 \mathrm{~min}$ at $30 \mathrm{mg}^{-1}$ and only $2 \mathrm{~min}$ at $35 \mathrm{mg}^{-1}$ to reach $90 \%$. Higher amounts were needed for the flocculation of S.acuminatus and C.reinhardtii (Fig. 3b, c). An FE of $90 \%$ was reached after 10 and 60 min, respectively, only after adding $60 \mathrm{mg}^{-1}$. Lower doses of $15 \mathrm{mg}^{-1}$ for Chlorella and $30 \mathrm{mg} \mathrm{l}^{-1}$ for Scenedesmus and Chlamydomonas resulted in insufficient algae recovery. Different behaviors in flocculation performance between the algae species were also observed in experiments displayed in Fig. 4.

Cationic, anionic and nonionic flocculants were compared with regard to the flocculation efficiency of the three algal species. First, the minimum concentration needed to achieve the highest FE was determined.

Figure 4 shows the highest FE achieved within the experiments, together with the corresponding amount of flocculant applied. The concentration is given in $\mathrm{mg}^{-1}$ and is indicated on top of each bar. Whereas Fig. 4a, $\mathrm{b}$ shows the results of cationic flocculants, Fig. 4c shows the FE for anionic and nonionic flocculants. 
Table 1 The 15 tested flocculants. Commercial name, polymer type, net charge and supplier are listed

\begin{tabular}{|c|c|c|c|c|c|}
\hline Commercial name & Polymer type & Net charge & $\begin{array}{l}\text { Stock } \\
\text { solution }[\mathrm{g} / \mathrm{l}]\end{array}$ & Supplier & $\begin{array}{l}\text { Price } \\
{[€ / \mathrm{kg}]}\end{array}$ \\
\hline Emfloc KC 750 & Starch & Cationic & 10 & $\begin{array}{l}\text { Emsland-Stärke GmbH } \\
\text { D-49824 Emlichheim }\end{array}$ & 1.25 \\
\hline Magnafloc LT 22S DWI & Polyacrylamide & Cationic & 5 & $\begin{array}{l}\text { BASF Corporation } \\
\text { Florhalm Park, USA }\end{array}$ & NA \\
\hline POLY SEPAR ${ }^{\circledR}$ CFL 25 & $\begin{array}{l}\text { Tannin, quaternary } \\
\text { ammonia compound }\end{array}$ & Cationic & 10 & $\begin{array}{l}\text { Separ Chemie GmbH } \\
\text { D-22926 Ahrensburg }\end{array}$ & 2.20 \\
\hline POLY SEPAR $^{\circledR} \mathrm{KW} 100$ & $\begin{array}{l}\text { Quaternary ammonia compound, } \\
\text { free of polyacrylamide }\end{array}$ & Cationic & 10 & & 2.40 \\
\hline POLY SEPAR ${ }^{\circledR} \mathrm{KW} 45$ & Polyacrylamide & Cationic & 10 & & 2.40 \\
\hline POLY SEPAR $^{\circledR}$ PK $55 \mathrm{H}$ & Polyacrylamide & Cationic & 2 & & 3.20 \\
\hline POLY SEPAR $^{\circledR}$ SK 72 & Starch & Cationic & 10 & & 3.00 \\
\hline POLY SEPAR $^{\circledR} \mathrm{KW} 745 \mathrm{H}$ & Polyacrylamide & Cationic & 10 & & 2.40 \\
\hline CFL 217 & Poly DADMAC & Cationic & 10 & & 2.20 \\
\hline CFL 229 & Poly DADMAC & Cationic & 10 & & 2.20 \\
\hline POLY SEPAR ${ }^{\circledR}$ AN 10 TW & Polyacrylamide & Anionic & 10 & & 3.50 \\
\hline Magnafloc LT 27 & Polyacrylamide & Anionic & 5 & BASF Corporation & NA \\
\hline Magnafloc LT 25 & Polyacrylamide & Anionic & 5 & Florhalm Park, USA & NA \\
\hline Magnafloc LT 20 & Polyacrylamide & Nonionic & 5 & & NA \\
\hline POLY SEPAR ${ }^{\circledR}$ AN20 & Polyacrylamide & Nonionic & 10 & $\begin{array}{l}\text { Separ Chemie GmbH } \\
\text { D-22926 Ahrensburg }\end{array}$ & 2.80 \\
\hline
\end{tabular}

The prices stated are price indications subjected to daily fluctuations and dependent on the ordered quantities NA price not available

PK55H reached the best FE at the lowest flocculant concentration. According to the manufacturers' information, $\mathrm{PK} 55 \mathrm{H}$ is a strongly cationic polymer of high molecular weight. Even at low PK55H concentrations of $1.5 \mathrm{mg} \mathrm{l}^{-1}$ for Chlorella and 2- and $4 \mathrm{mg} \mathrm{l}^{-1}$ for Scenedesmus and Chlamydomonas, high FE of $<95 \%$ was attained (Fig. 4b). This flocculant is suitable for all the three cell types, resulting in large and dense flocs (Fig. 5).

The cationic charge of a flocculant is dependent on the amount of cationic charged monomers bound to the polymer chain and can vary between 0 and $100 \%$ (Gerde et al. 2014). According to the manufacturers' information, KW 100 and KW 45 are both polymers with similar polymer structure, merely differing in the amount of cationic groups attached to the polymer chain. The polymer chain of KW100 is completely substituted with cationic groups resulting in $\mathrm{FE}<90 \%$. In the case of KW45, only $35 \%$ of the available sites are covered with cationic groups showing lower FE between 40 and $80 \%$. This result confirms the assumption that the degree of cationic ionization affects harvesting efficiencies. A higher cationic charge of a polymer results in better FE.

CFL217, CFL 229 and CFL 25 belong to the group of polyDADMACS (Diallyldimethyl ammonium chloride). According to the manufacturer's information the molecular weight of these polymers is low with a high cationic charge. The results showed FE of 80-100\% with the best results for Scenedesmus. In the case of CFL25, the results for the three tested microalgae differ (Fig. 4). Chlorella cells were coagulated with an FE of $<90 \%$ resulting in very fine and small flocs (Fig. 5). Chlamydomonas cells, however, only achieved FE of $20 \%$. The specific surface area of the cells is another important factor to consider. The smaller size of Chlorella cells $(2-10 \mu \mathrm{m})$ give them a smaller surface area compared to Scenedesmus and Chlamydomonas cells $(10-30 \mu \mathrm{m})$. Polymers of low molecular weight can entirely absorb onto the cell surface forming regions with cationic nature. These regions can bind negatively charged regions of other algal cells. Larger cells might not be bound effectively resulting in lower FE. 

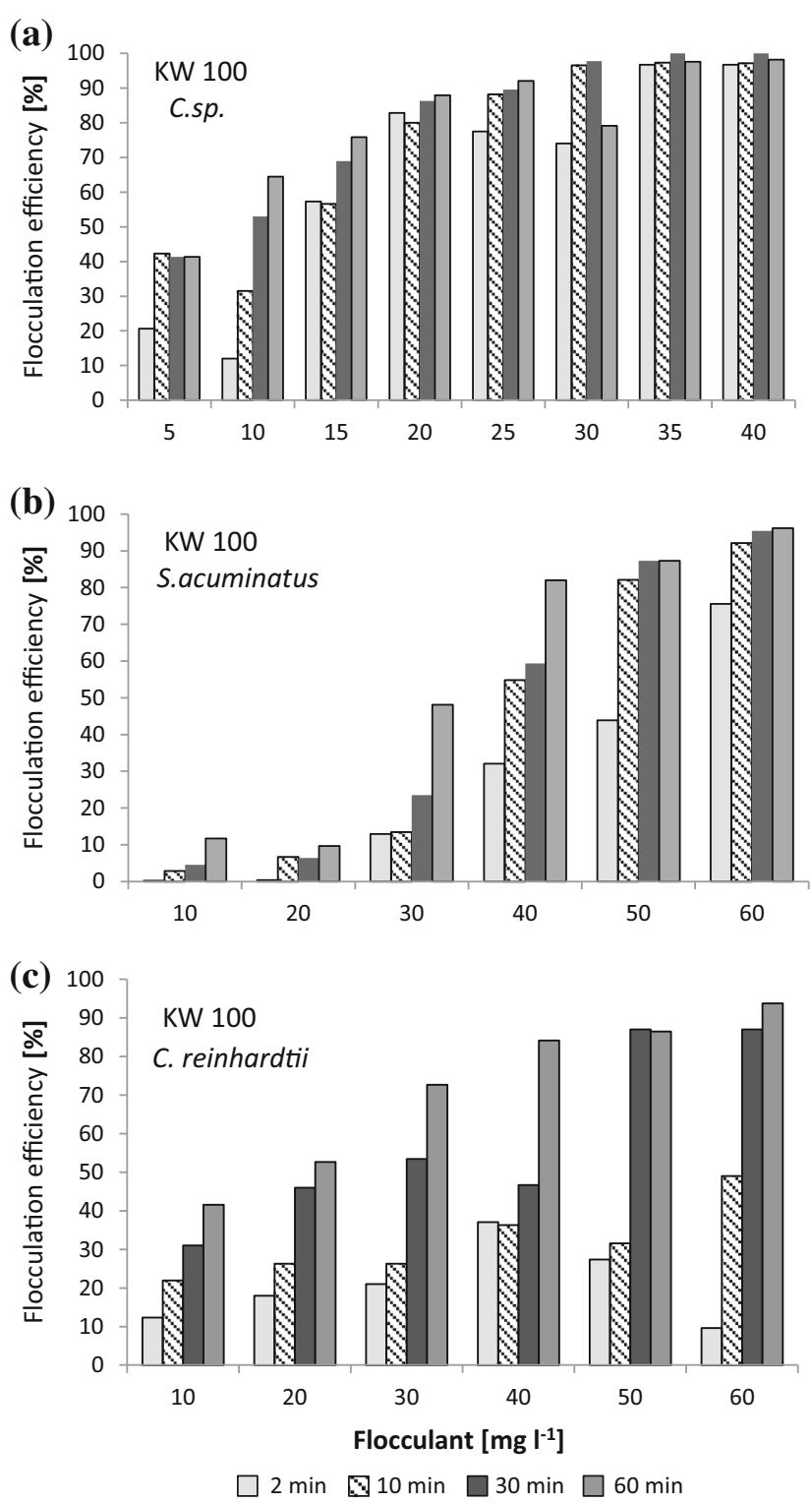

Fig. 3 Example of a flocculation experiment using the cationic flocculant KW100. Flocculation efficiencies for harvesting Chlorella sp. (a), Scenedesmus acuminatus (b) and Chlamydomonas reinhardtii (c) cultures are shown with different doses of flocculant $\left(\mathrm{mg}^{-1}\right)$. Optical density measurements were conducted after 2, 10, 30 and $60 \mathrm{~min}$

Several microalgae have been subjected to flocculation experiments such as Chlorella, Chlamydomonas, Scenedesmus, Schizochytrium, Muriellopsis, and Phaeodactylum resulting in different FE per milligram of flocculant (Gerde et al. 2014; Granados et al. 2012; Harith et al. 2009; Papazi et al. 2010; Rashid et al. 2013; Sirin et al. 2012). Chlorella sp., Scenedesmus acuminatus and Chlamydomonas reinhardtii are commonly used laboratory strains and model organisms for algal research (Harris 2001; Mandal and Mallick 2009; Safi et al. 2014; Sanchez et al. 2008). By testing these three chlorophytes, the influence of different sizes, morphologies and motilities of the flocculation efficiency should be verified. Considering the varying flocculant concentrations needed to floc the different algal species, the hypothesis that related species (Chlorophyceae) show similar flocculation behavior cannot be positively proved.

Figure 4c shows the results gained with nonionic (AN 20, LT20) and anionic flocculants (LT25, LT27 and AN10TW). No flocculation was observed for these flocculants, whichever dose was used.

At neutral $\mathrm{pH}$, the cell surface of microalgae is usually negatively charged due to functional groups on the algal surface (Golueke and Oswald 1970). Therefore, generally positively charged flocculants are 

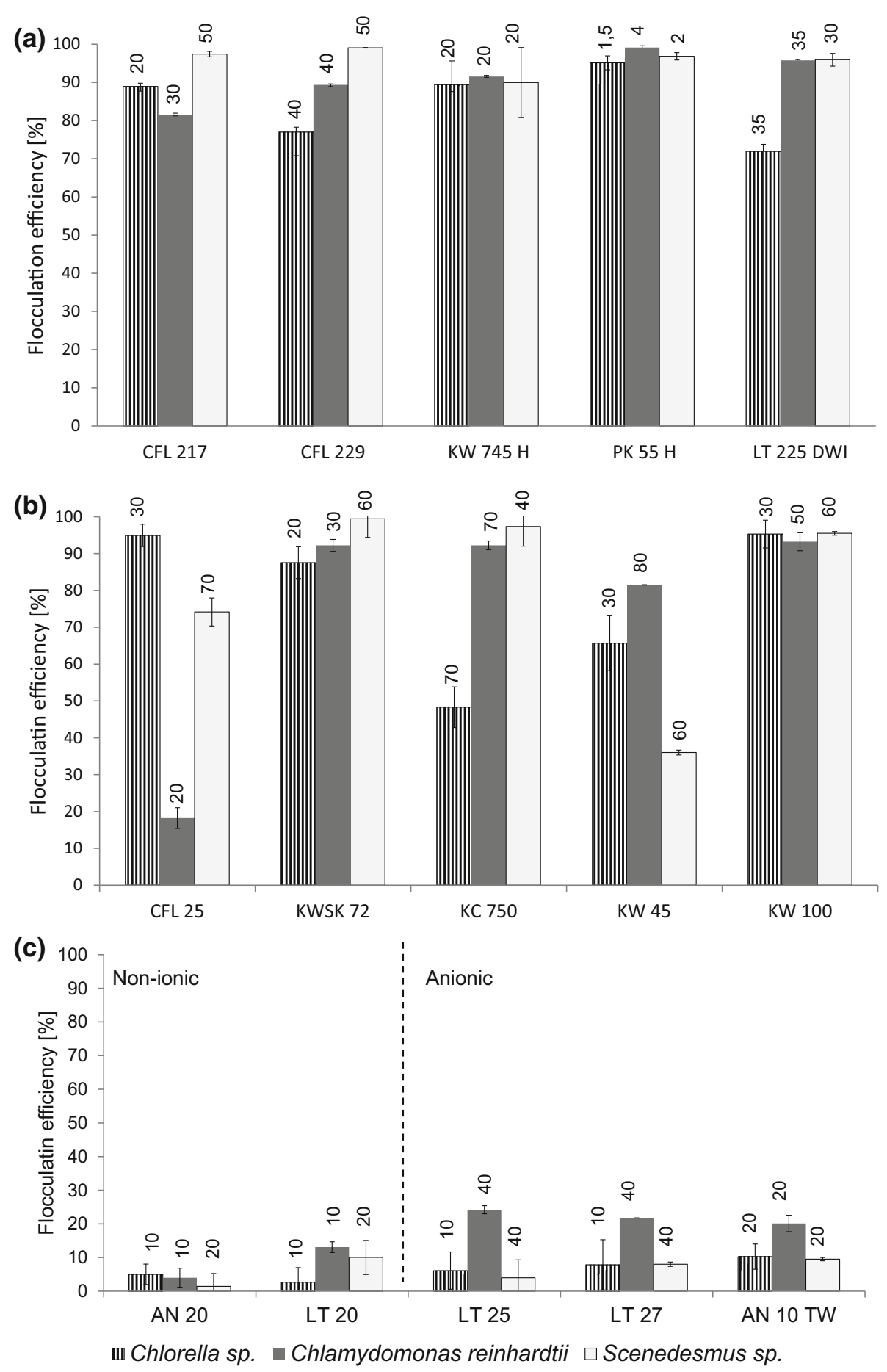

Fig. 4 Flocculation efficiencies of 15 polyelectrolytes with Chlorella sp., Chlamydomonas reinhardtii and Scenedesmus acuminatus. Cationic (a, b), anionic and nonionic (c) flocculants were tested and the most efficient concentration $\left(\mathrm{mg}^{-1}\right)$ determined and displayed on top of each bar. The incubation time was $30 \mathrm{~min}$ in all experiments

recommended to neutralize the negatively charged cell surface of the microalgae (Granados et al. 2012; Tenney et al. 1969). Flocculation with polymers of the same charge can also be achieved by other mechanisms than charge neutralization, such as inter-particle bridging with long polymers. Tenney and co-workers reported the attachment of anionic polymers to the algal surface, but no floc formation in the solution was observed. Strongly anionic polymers can be effective in basic media. Harith et al. described an effective use of 


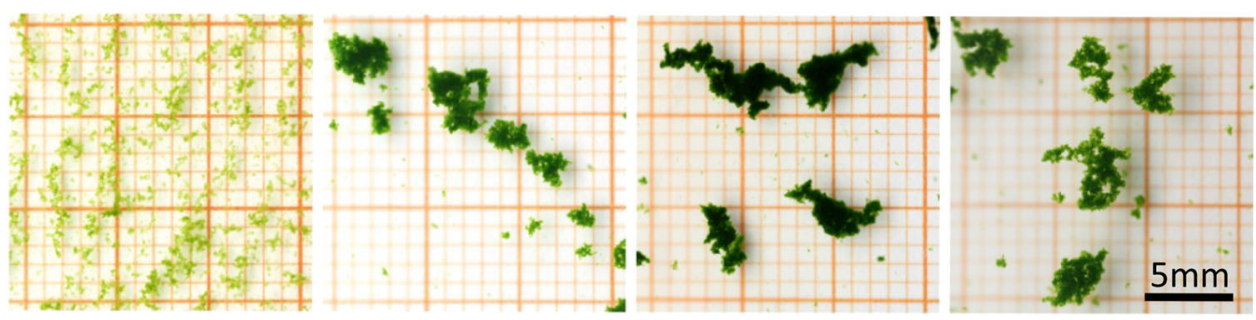

Fig. 5 Flocs produced by the flocculants CFL25, KW100, PK55H and KC750 (from left to right). The picture shows the result of a flocculation using Scenedesmus acuminatus

anionic flocculants only after algal surface charge neutralization by $\mathrm{pH}$ adjustments. The application of flocculant LT25 and LT 27 at a pH of 10.2 with the microalgae Chaetoceros calcitrans resulted in flocculation efficiencies above $90 \%$ (Harith et al. 2009). The increase of $\mathrm{pH}$ before flocculation might improve FE, but negatively affect media recycling and thereby cost-effectiveness.

Based on the results, the use of anionic and nonionic flocculants cannot be recommended for harvesting of Chlorella, Scenedesmus and Chlamydomonas cells. The results gained positively prove the hypothesis that cationic flocculants are more effective than anionic or nonionic polymers in respects of FE.

For industrial application, the recycling of the growth media after cell harvest is an important factor in costeffectiveness. Residues and color changes after flocculation experiments were reported, indicating that medium recycling after flocculation was not feasible (Sirin et al. 2012). It was necessary to verify if remaining flocculant particles do not negatively affect cell growth if the media are led back into the culture vessel after cell separation. A recycling experiment was conducted over a period of 8 weeks using Chlamydomonas cultures. The biomass was harvested weekly using the flocculant PK55H or centrifugation and the supernatant was returned into the bioreactor. Figure 6 shows the results of the growth of the microalgae by optical density (OD) measurements. After each harvesting, the optical density $(750 \mathrm{~nm})$ was adjusted to 1.5 to improve the light conditions for the algae. No differences between the flocculated cultures and the cultures harvested by centrifugation were visible by comparing OD values.

Although the OD values between flocculated and centrifuged cultures remained similar, the biomass concentration changed. After 10 days, the formation of aggregates was visible under the microscope and the ratio between OD and BTM changed (Table 2; Fig. 6). Although the OD values remained the same, due to the aggregates, more cells were present in the cultures, resulting in higher dry biomass values.

Table 2 lists the dry biomass values measured every week before harvesting. The data from the control and the recycling experiment differed significantly. After 8 weeks of cultivation, the dry biomass of the recycling

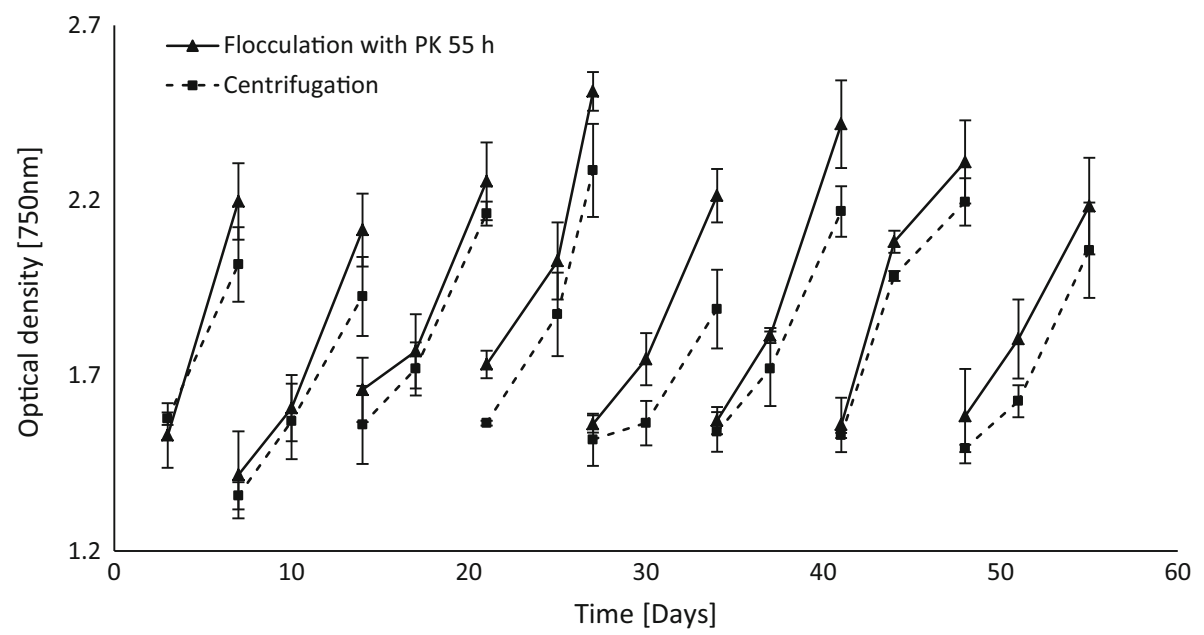

Fig. 6 Media reuse after flocculation. Over a period of 8 weeks the culture was harvested weekly by flocculation or centrifugation and the supernatant enriched with nutrients was led back into the bioreactor. The graph displays the optical density measurements registered three times per week 
Table 2 Dry biomass concentration in $\mathrm{g}^{-1}$

\begin{tabular}{lll}
\hline Day & $\begin{array}{l}\text { Flocculation } \\
\text { MV } \pm \text { SD }\end{array}$ & $\begin{array}{l}\text { Centrifugation } \\
\text { MV } \pm \text { SD }\end{array}$ \\
\hline 0 & $1.52 \pm 0$ & $1.52 \pm 0$ \\
3 & $1.49 \pm 0.16$ & $1.47 \pm 0.04$ \\
10 & $2.18 \pm 0.22$ & $1.73 \pm 0.01$ \\
17 & $2.14 \pm 0.03$ & $1.60 \pm 0.18$ \\
25 & $2.36 \pm 0.17$ & $1.50 \pm 0.11$ \\
30 & $2.09 \pm 0.04$ & $1.34 \pm 0.10$ \\
37 & $2.42 \pm 0.12$ & $1.59 \pm 0.04$ \\
44 & $2.53 \pm 0.08$ & $1.68 \pm 0.22$ \\
51 & $2.75 \pm 0.18$ & $1.72 \pm 0.14$ \\
\hline
\end{tabular}

During the media reuse growth experiment, the dry biomass was determined every week before harvesting

experiment was $1 \mathrm{~g}^{-1}$ higher than that of the control cultures, although the OD values remained similar. The growth rates, however, indicate that neither the added flocculant nor a possible accumulation of algal products negatively affected cell growth.

Over a period of 8 weeks, the culture media were successfully recycled after flocculation. The hypothesis that the reuse of the media is applicable was positively proved.

\section{Conclusion}

The flocculation efficiency of microalgae for cell harvest was significantly influenced by the net charge of the tested polymer. Cationic flocculants achieved the highest flocculation efficiencies, whereas anionic and nonionic flocculants resulted in no or insufficient flocculation. The amount of flocculant needed varied among the chemicals from 1.5 to $70 \mathrm{mg} \mathrm{l}^{-1}$, but also between the algae species (e.g., CFL25 with $30 \mathrm{mg}^{-1}$ for Chlorella and $70 \mathrm{mg}^{-1}$ for Scenedesmus). Because of high flocculation efficiencies above $95 \%$ at low concentrations of $1.5 \mathrm{mg}^{-1}$, the cationic polyelectrolyte PK55H was selected for recycling experiments. No limitation in culture growth and biomass production was detected, although an aggregation of the cells was visible. The results showed that chemical flocculation is a simple, efficient and inexpensive method for harvesting different types of microalgae.

Acknowledgments We thank Separ Chemie GmbH and Emslandstärke GmbH for supplying the tested flocculants. Furthermore, we would like to thank Angela Rosien for critical reading of our manuscript. This research was financially supported by the project ModuLES funded by the German aerospace association (DLR)(Grant number: 50WB1265).

Open Access This article is distributed under the terms of the Creative Commons Attribution 4.0 International License (http:// creativecommons.org/licenses/by/4.0/), which permits unrestricted use, distribution, and reproduction in any medium, provided you give appropriate credit to the original author(s) and the source, provide a link to the Creative Commons license, and indicate if changes were made.

\section{References}

Chisti Y (2007) Biodiesel from microalgae. Biotechnol Adv 25:294-306

Gerde JA, Yao LX, Lio JY, Wen ZY, Wang T (2014) Microalgae flocculation: impact of flocculant type, algae species and cell concentration. Algal Res Biomass Biofuels Bioprod 3:30-35

Golueke CG, Oswald WJ (1970) Surface properties and ion exchange in algae removal. J Water Pollut Control Fed 42:R304

Granados MR, Acien FG, Gomez C, Fernandez-Sevilla JM, Grima EM (2012) Evaluation of flocculants for the recovery of freshwater microalgae. Bioresour Technol 118:102-110

Grima EM, Belarbi EH, Fernandez FGA, Medina AR, Chisti Y (2003) Recovery of microalgal biomass and metabolites: process options and economics. Biotechnol Adv 20:491-515

Harith ZT, Yusoff FM, Mohamed MS, Din MSM, Ariff AB (2009) Effect of different flocculants on the flocculation performance of microalgae, Chaetoceros calcitrans, cells. Afr J Biotechnol 8:5971-5978 
Harris EH (2001) Chlamydomonas as a model organism. Ann Rev Plant Physiol Plant Mol Biol 52:363-406

Hudson HE, Wagner EG (1981) Conduct and uses of jar tests. J Am Water Works Assoc 73:218-223

Lee AK, Lewis DM, Ashman PJ (2009) Microbial flocculation, a potentially low-cost harvesting technique for marine microalgae for the production of biodiesel. J Appl Phycol 21:559-567

Lee AK, Lewis DM, Ashman PJ (2013) Harvesting of marine microalgae by electroflocculation: the energetics, plant design, and economics. Appl Energy 108:45-53

Mandal S, Mallick N (2009) Microalga Scenedesmus obliquus as a potential source for biodiesel production. Appl Microbiol Biotechnol 84:281-291

Mata TM, Martins AA, Caetano NS (2010) Microalgae for biodiesel production and other applications: a review. Renew Sustain Energy Rev 14:217-232

Papazi A, Makridis P, Divanach P (2010) Harvesting Chlorella minutissima using cell coagulants. J Appl Phycol 22:349-355

Posten C, Walter C (2012) Microalgal biotechnology: potential and production. de Gruyter, Berlin

Rashid N, Rehman SU, Han JI (2013) Rapid harvesting of freshwater microalgae using chitosan. Process Biochem 48:1107-1110

Safi C, Zebib B, Merah O, Pontalier PY, Vaca-Garcia C (2014) Morphology, composition, production, processing and applications of Chlorella vulgaris: a review. Renew Sustain Energy Rev 35:265-278

Salim S, Bosma R, Vermue MH, Wijffels RH (2011) Harvesting of microalgae by bio-flocculation. J Appl Phycol 23:849-855

Sanchez JF, Fernandez JM, Acien FG, Rueda A, Perez-Parra J, Molina E (2008) Influence of culture conditions on the productivity and lutein content of the new strain Scenedesmus almeriensis. Process Biochem 43:398-405

Sirin S, Trobajo R, Ibanez C, Salvado J (2012) Harvesting the microalgae Phaeodactylum tricornutum with polyaluminum chloride, aluminium sulphate, chitosan and alkalinity-induced flocculation. J Appl Phycol 24:1067-1080

Tenney MW, Echelber WF, Schuessl RG, Pavoni JL (1969) Algal flocculation with synthetic organic polyelectrolytes. Appl Microbiol 18:965

Uduman N, Qi Y, Danquah MK, Forde GM, Hoadley A (2010) Dewatering of microalgal cultures: a major bottleneck to algaebased fuels. J Renew Sustain Energy 2:15

Uduman N, Bourniquel V, Danquah MK, Hoadley AFA (2011) A parametric study of electrocoagulation as a recovery process of marine microalgae for biodiesel production. Chem Eng J 174:249-257

Vandamme D, Foubert I, Meesschaert B, Muylaert K (2010) Flocculation of microalgae using cationic starch. J Appl Phycol 22:525-530

Vandamme D, Pontes SCV, Goiris K, Foubert I, Pinoy LJJ, Muylaert K (2011) Evaluation of electro-coagulation-flocculation for harvesting marine and freshwater microalgae. Biotechnol Bioeng 108:2320-2329

Vandamme D, Foubert I, Fraeye I, Meesschaert B, Muylaert K (2012) Flocculation of Chlorella vulgaris induced by high pH: role of magnesium and calcium and practical implications. Bioresour Technol 105:114-119

Wijffels RH, Barbosa MJ (2010) An outlook on microalgal biofuels. Science 329:796-799

Winckelmann D, Bleeke F, Bergmann P, Klöck G (2014) Growth of Cyanobacterium aponinum influenced by increasing salt concentrations and temperature. 3 Biotech 5:253-260

Wu ZC, Zhu Y, Huang WY, Zhang CW, Li T, Zhang YM, Li AF (2012) Evaluation of flocculation induced by pH increase for harvesting microalgae and reuse of flocculated medium. Bioresour Technol 110:496-502

Xu L, Wang F, Li HZ, Hu ZM, Guo C, Liu CZ (2010) Development of an efficient electroflocculation technology integrated with dispersed-air flotation for harvesting microalgae. J Chem Technol Biotechnol 85:1504-1507

Zheng HL, Gao Z, Yin JL, Tang XH, Ji XJ, Huang H (2012) Harvesting of microalgae by flocculation with poly (gamma-glutamic acid). Bioresour Technol 112:212-220

Zhou WG, Min M, Hu B, Ma XC, Liu YH, Wang Q, Shi J, Chen P, Ruan R (2013) Filamentous fungi assisted bio-flocculation: a novel alternative technique for harvesting heterotrophic and autotrophic microalgal cells. Sep Purif Technol 107:158-165 